\title{
IMPACTOS DAS EMPRESAS SOCIAIS EM MINAS GERAIS: DESAFIOS E CONTRADIÇÕES DE SUA DISPERSÃO ESPACIAL
}

Ramon Jung Pereira ${ }^{1}$

Tatiane Lucia De Melo ${ }^{1}$

Frederico Dornellas Martins Quintão ${ }^{1}$

Armindo Dos Santos De Sousa Teodósio ${ }^{1}$

\footnotetext{
${ }^{1}$ Pontifícia Universidade Católica de Minas Gerais - PUC Minas
} 


\section{IMPACTOS DAS EMPRESAS SOCIAIS EM MINAS GERAIS: DESFIOS E CONTRADIÇÕES DE SUA DISPERSÃO ESPACIAL}

\section{Resumo:}

O presente estudo é o primeiro de um conjunto de pesquisas sobre Perfil e Ecossistemas das Empresas Sociais no estado de Minas Gerais. Trata-se de assunto que envolve diversos atores e possibilidades de análise, sendo necessário sua realização em etapas, estruturadas de acordo com as informações obtidas e dados coletados. Não obstante, por ser aplicado em um estado que possui enorme extensão geográfica e complexa rede sócio, econômica, cultural e histórica, é preciso que essa investigação leve em consideração as peculiaridades de cada região, a fim de entender as características e propostas dos negócios que são instalados. Dessa forma, o artigo realizou uma abordagem conceitual e coleta de informações em grupos de pesquisa, mecanismos de apoio e plataformas digitais para produzir o mapeamento regional dos negócios de impacto presentes atualmente em Minas Gerais, constatando a alta concentração de iniciativas em determinadas regiões e a disparidade presente entre localidades do estado.

Palavras-chave: Empresa Social, Negócio de Impacto Social, Minas Gerais, Desigualdades Regionais

\section{Introdução}

Ao longo dos dois últimos séculos as relações entre capital, trabalho e natureza tem produzido avanços dentro do que se convencionou entender como desenvolvimento econômico e também significativos impactos negativos na natureza e nas relações sociais. Como aponta o relatório produzido pela ONU (2012), quase um bilhão de pessoas vivem em situação de pobreza e não possuem condições básicas de alimentação. A degradação do meio ambiente, a escassez de recursos, a desigualdade social e os altos índices de miséria são assuntos que vem ganhando centralidade em debates e merecendo a atenção de organismos internacionais, instituições públicas, organizações da sociedade civil e empresas privadas. (ROSOLEN et al, 2014).

Uma série de empreendimentos que vão além da convencional busca pela rentabilidade, levando em consideração públicos em situação de pobreza e vulnerabilidade, tem se disseminado pelo mundo. Considerando este cenário, emerge a noção de Empresas Sociais (ES), que conforme argumenta Mair (2006), são aqueles cujas atividades visam combater problemas socioambientais através de empreendimentos ou organizações que atuam no ambiente de mercado como ofertadoras de produtos e serviços. Diversos estudos têm sido feitos buscando não apenas chegar a um consenso sobre o conceito ou desenvolver abordagens distintas sobre o mesmo fenômeno (COMINI et al, 2012; ROMANI- DIAS; MSWAKA, ALUKO, 2015; IISUKA, 2016; BESLEY, GHATAK, 2017), mas também compreender os contextos nacional e regionais em diversos países do mundo, incluindo o Brasil, que caracterizam a difusão desses empreendimentos (DEFOURNY, NYSSENS; 2017). 
O presente artigo se propõe a realizar o mapeamento de ES atuantes no estado de Minas Gerais, visando identificar como estão distribuídas nas regiões do estado, destacando suas áreas de impacto e públicos impactados e, consequentemente, as possíveis variáveis que influenciam diretamente ou indiretamente na sua dispersão geográfica. $\mathrm{O}$ estado de Minas Gerais é marcado por desigualdades regionais que expressam diferentes condições de vulnerabilidade social, pobreza e riscos ambientais no seio de sua população e comunidades. Há locais com elevado PIB per capita e IDH, ao mesmo tempo em que podem ser encontradas regiões marcadas pela permanência da pobreza, desigualdade e vulnerabilidade. Minas Gerais, nesse sentido, espelha as contradições e o desenvolvimento desigual que marcam o próprio Brasil ao longo de sua trajetória como nação. Ao se compreender a dispersão espacial das empresas sociais no estado e os elementos que a impactam, procura-se entender se há uma convergência entre demandas socioambientais e a emergência de ES no contexto regional analisado. Essa relação de convergência (ou não) se constitui em uma das questões centrais para investigações sobre a relevância e impacto das Empresas Sociais, tema pouco investigado no contexto brasileiro, ainda que haja estudos antigos e clássicos sobre tais configurações entre outros países e regiões, notadamente no continente europeu.

Para responder a pergunta de pesquisa, o artigo se estrutura com uma revisão teórica na qual são apresentadas diferentes abordagens sobre ES, adotando uma noção crítica sobre esse fenômeno. Em seguida, é feita uma descrição dos procedimentos metodológicos da investigação, que se baseia na coleta e análise de dados secundários. Na discussão dos resultados, a partir da apresentação de mapas, figuras e gráficos, são apontados os dados encontrados e discutidas as implicações da forma como as ES se distribuem geograficamente em Minas Gerais, suas atuações, impactos e públicos afetados.

\section{Uma Compreensão Crítica sobre as Empresas Sociais}

Ao se abordar temas relacionados a negócios, comumente encontram-se os tradicionais, ligados à competitividade e lucratividade dos empreendimentos, e os que geram impactos sociais e ambientais. Em síntese, se por um lado os negócios tradicionais têm "a função social de gerar lucro aos sócios" (FRIEDMAN, 1970), as Empresas Sociais buscam, da mesma forma, gerar lucro. Entretanto, este tipo de negócio apresenta a função social de ser direcionado para resolução de problemas socioambientais diversos (BARKI, 2015). Esses negócios buscam equilíbrio entre a obtenção de lucros econômicos e objetivos sociais, além de possuírem autonomia financeira, ponto este que seria uma das principais características que diferenciaria as ES das Organizações da Sociedade Civil. Contudo, faz-se presente diversas abordagens que visam explicar o fenômeno das Empresas Sociais (ABRAMOVAY, 2012), sendo as principais: Negócios da Base da Pirâmide (PRAHALAD; HART, 2002), Negócios Sociais (YUNUS, 2006) e Negócios Inclusivos (TEODÓSIO; COMINI, 2012).

No final da década de 90, autores como Prahalad et al. (2005) iniciaram estudos acerca de Negócios da Base da Pirâmide, através de debates sobre a criação de modelos empresariais voltados para atendimento de necessidades das populações mais pobres e vulneráveis. Prahalad (2010) afirma que devemos parar de tratar os mais pobres como vítimas, passando a reconhecê-los como empreendedores criativos e conscientes. Dessa forma, poderiam surgir muitas oportunidades de empreendimentos voltados à resolução de problemas sociais e ambientais. 
Estudos como o de Prahalad (2010) buscam demonstrar como negócios voltados para a camada mais pobre da população mundial (a base da pirâmide econômica), e não somente para a população de alto poder aquisitivo, podem gerar lucro e ao mesmo tempo contribuir para a erradicação da pobreza. Isso pode ser dinamizado através da geração de inovação, de novas tecnologias, produtos, serviços e modelos de negócios, além da promoção de parcerias entre empresas, organizações da sociedade civil, governos e membros das comunidades locais (MIRON JAPPE, 2013). Prahalad (2010) chama atenção sobre a existência de 4 (quatro) bilhões de pobres, que poderiam ser a força motriz de uma nova etapa de prosperidade econômica.

Hart (2005) afirma que as oportunidades de fazer negócios com a população de baixa renda também representam uma mudança de entendimento no investimento externo. De acordo com o autor, investir em países em desenvolvimento tem sido uma prática comum, porém, as empresas multinacionais que se instalam em países subdesenvolvidos visam uma pequena porcentagem da população dessas nações que têm alta renda para consumir seus produtos, e terminam atendendo apenas um mercado consumidor que tem perfil semelhante ao do consumidor médio norte americano ou europeu.

Como apontado por Petrini et al. (2016), as abordagens defendidas por Hart (2005) e Prahalad (2005) vieram em um momento de saturação dos mercados desenvolvidos, pressionando as organizações a olharem para a base da pirâmide. A partir desse cenário, que demanda a criação de novas soluções e estratégias para enfrentamento da pobreza e da desigualdade social, ao longo das últimas décadas têm surgido propostas inúmeras formas de trabalho com a base da pirâmide.

Comini et al. (2012) afirmam que a chamada Base da Pirâmide tem se apresentando como um campo fértil para o surgimento de um novo tipo de organização capaz de articular duas metas até então vistas como incompatíveis: a sustentabilidade financeira e geração de valor social. Iniciativas que seguem esse propósito recebem vários nomes diferentes, sendo que algumas são semelhantes e outras se diferem no que tange à forma como devem ser gerenciadas e as metas que devem estabelecer e com as quais devem ser avaliadas ou analisadas.

A origem do termo "Negócio social" se dá partir de alguns conceitos da economia capitalista em seu processo de implementação utilizando-se da literatura sobre negócios convencionais (YUNUS; MOINGEON; LEHMANN-ORTEGA, 2009). Neste sentido, o modelo de negócio social não se diferenciaria em sua plenitude de um negócio tradicional, porém, seria orientado pelos princípios de concepção de um empreendimento com foco social.

O conceito de empresa social colocado por Yunus (2006), que o assume como sinônimo de negócio social, exige aprofundamento para a compreensão de suas implicações tanto teóricas quanto em termos práticos no que tange à organização de empreendimentos sociais. Comini (2016) afirma que é possível encontrar na literatura três correntes que explicam os negócios sociais: a perspectiva europeia, a perspectiva estadunidense e a perspectiva predominante em países em desenvolvimento, que considera negócios sociais como empreendimentos socioambientais que visam a redução da pobreza e a transformação social.

De forma sucinta, pode-se mencionar a abordagem americana na qual "negócio social" é entendido como sendo "qualquer tipo de organização envolvida em atividades de valor 
social significativo, ou que produzam bens e serviços para fomentar um propósito social, independentemente da forma legal." (JOÃO, 2012, p.3). No caso da perspectiva estadunidense, como afirma Ferreira et al (2014), a Empresa Social está vinculado a ideia de organizações privadas com lógica de mercado para a solução de problemas sociais.

Dentro da abordagem europeia, a Emergence of Social Enterprises in Europe (EMES), formada por um grupo de estudiosos que pesquisam temas a respeito do terceiro setor no continente europeu, argumenta que existe um tipo ideal de empresa social, ou um "conjunto de princípios orientadores", aos quais todos os empreendimentos sociais devem se basear, independentemente da forma que possuem (Defourny e Nyssens, 2012). Nesse sentido, as empresas sociais podem ser definidas como organizações com um objetivo explícito de beneficiar comunidade através da geração de empregos e da busca de objetivos sociais acordados e mensuráveis. (COMINI et al., 2013; MUNOZ, FARMER, WINTERTON, \& BARRAKET, 2015; AMBROSE-OJI, LAWRENCE \& STEWART, 2015)

A perspectiva dos países em desenvolvimento associa ao termo Empresas Sociais o combate à desigualdade e à pobreza como elementos centrais dos empreendimentos caracterizados como tal. De acordo com Comini (2016), vários autores dessa corrente defendem que a caracterização de uma Empresa Social está mais voltada para a sua intencionalidade do que para uma definição jurídica em si. Nesse sentido, é importante que não seja apenas autossustentável e rentável, mas que gere benefícios socioambientais e transformação das condições de vida de determinada população, principalmente aquelas em situação de vulnerabilidade (COMINI, 2016).

Quando se aborda a temática das Empresas Sociais é importante compreender que o papel que o lucro possui nesses negócios se difere sensivelmente dos negócios tradicionais, cujo objetivo central é produzir lucros. Suas atividades têm como objetivo fim o resultado financeiro e competitivo gerado ao final do processo. Nas Empresas Sociais, o objetivo principal é gerar resultado socioambiental positivo, tendo o lucro em segundo plano para suportar a criação de impacto cada vez maior com o decorrer das atividades (BRANDÃO; CRUZ; ARIDA, 2013). O lucro é meio e não fim, nas Empresas Sociais, segundo a abordagem de YUNUS (2017).

Teodósio e Comini (2012) afirmam que o termo Negócios Inclusivos ainda é recente na literatura brasileira, sendo uma expressão incomum no cotidiano. De acordo com os autores, os Negócios Inclusivos envolvem a população de baixa renda tanto no papel de consumidores, quanto de empregados ou proprietários, promovendo a participação dessas pessoas diretamente no processo de desenvolvimento econômico e sustentável. Nesse sentido, Moura (2011) define o modelo de Negócios Inclusivos como algo que não abrange apenas a combinação de sustentabilidade financeira e geração de valor social, mas envolve também a efetiva inserção da população de baixa renda no processo produtivo de um negócio, não o colocando somente como consumidor final. Corroborando tal perspectiva, Petrini et al. (2016) afirmam que esses negócios envolvem qualquer produto ou serviço, desde que inclua a população de baixa renda no processo de produção, fornecimento ou distribuição, sendo que seus clientes podem ser qualquer pessoa, inclusive e sobretudo a população de baixa renda.

Na presente investigação, adotou-se a concepção dos países em desenvolvimento sobre ES. Com isso, a abordagem crítica sobre o fenômeno das ES não pode se furtar a compreender em que medida esses empreendimentos são efetivamente orientados para população em 
situação de vulnerabilidade socioambiental ou em situação de pobreza e até que ponto essas atividades de mercado conseguem alterar a realidade de desigualdade que marca a sociedade brasileira.

Compreender a delimitação de cada uma dessas abordagens e deixar claro a orientação teórica que guia a pesquisa se faz essencial para fundamentar a análise das informações que serão expostas a seguir, na qual foi investigado o contexto regional das ES mineiras. Conforme argumenta-se também nos tópicos subsequentes, a realidade socioeconômica, cultural, política, ambiental e regional brasileira demanda abordagens sobre o fenômeno das ES que consigam problematizar suas possibilidades e limitações de alterar contextos marcados por profunda exclusão social, desigualdade e vulnerabilidade de muitos segmentos e grupos sociais, que se acabam se tornando invisíveis para a sociedade e para as pesquisas que não se orientam por uma visão crítica do fenômeno das empresas de impacto social.

\section{Procedimentos Metodológicos}

Estabelecido o foco conceitual de abordagem, a etapa seguinte se deu pela busca por ES em Minas Gerais, decisão essa que foi apoiada pela relevância nacional da região. Segundo o IBGE (2016), Minas Gerais é caracterizado como um dos maiores estados brasileiros com cerca de 19.597.330 habitantes, distribuídos em 853 municípios. Além disso, apresenta um PIB que gira na casa dos $\mathrm{R} \$ 287$ bilhões, sendo que pouco mais de $50 \%$ da população do estado - 9,94 milhões de pessoas - são consideradas economicamente ativas.

Como estratégia de coleta de dados, optou-se por obter informações juntamente aos grupos de pesquisa que realizam estudos na temática de ES e em organismos de apoio ao desenvolvimento de negócios dessa natureza, sendo caracterizados por aceleradoras e incubadoras presentes nas diferentes regiões do estado. Bases secundárias, ou seja, outros estudos que traziam bases com informações sobre incidência e localização de ES também foram mobilizadas na coleta e tratamento dos dados. Dentro desse contexto, analisou-se a base de dados da Pipe Social, uma plataforma nacional que pesquisa e divulga informações sobre contexto de crescimento e desenvolvimento de "Negócios de Impacto Social" brasileiros (PIPE, 2017). Somado a isso, foram analisados documentos, relatórios e artigos públicos cedidos pelas próprias ES em sites e mídias institucionais em busca do entendimento de sua atuação e dos públicos que seriam afetados diretamente ou indiretamente por suas atividades.

Objetivando a confiabilidade do banco de dados, foi realizada a triangulação dos dados advindos das fontes de evidências, em busca de possíveis contradições e problemas. Além disso, em meio a tentativa de garantir que essas empresas de fato existiriam, optou-se pela procura na internet e em redes sociais sobre sinais de que as atividades das empresas selecionadas estavam sendo realizadas. Entretanto, não foi possível identificar todas as empresas por essa abordagem, uma vez que muitas delas não utilizavam estratégias digitais, nem mesmo tinham intuito de divulgar o trabalho, devido ao possível "estágio de vida".

Para constatação dos resultados, realizou-se a tabulação, tratamento e organização dos dados pelo "Microsoft Office Excel", para preparação para a análise quantitativa. Uma vez organizados, os dados foram transferidos para a ferramenta "Microsoft Power BI", visando a realização das análises de frequências georreferenciadas e a triangulação dos resultados encontrados no que se refere a localização, atuação, impacto e públicos impactados. Tal 
modelagem e análise foi essencial para o intuito de trazer importantes constatações sobre o contexto geral das Empresas Sociais identificadas no estado de Minas Gerais.

\section{Minas é logo ali?: uma análise da dispersão geográfica de Empresas Sociais}

Tendo tais aspectos como base, a primeira etapa do estudo foi identificar as empresas sociais presentes no estado de Minas Gerais. Foram localizadas informações relevantes sobre 200 ES presentes no estado de Minas Gerais.

É possível afirmar que os principais achados se concentram nas cidades de Belo Horizonte (123), Uberlândia (9), Poços de Caldas (5), Nova Lima (4), Contagem (3), Itajubá (3), Juiz de Fora (3), Pouso Alegre (3) e Sete Lagoas (3), enquanto em outras 29 cidades foi possível identificar entre uma ou duas ES. Para ilustrar esses dados, optou-se por utilizar a modelagem de dados a partir do software "Microsoft Power BI", realizando análises de frequências georreferenciadas com a abordagem de "mapa de bolhas". Nesse modelo, cada ponto da rede é representado por uma "bolha", sendo que sua cor e seu tamanho determinam sua força representativa perante as demais.

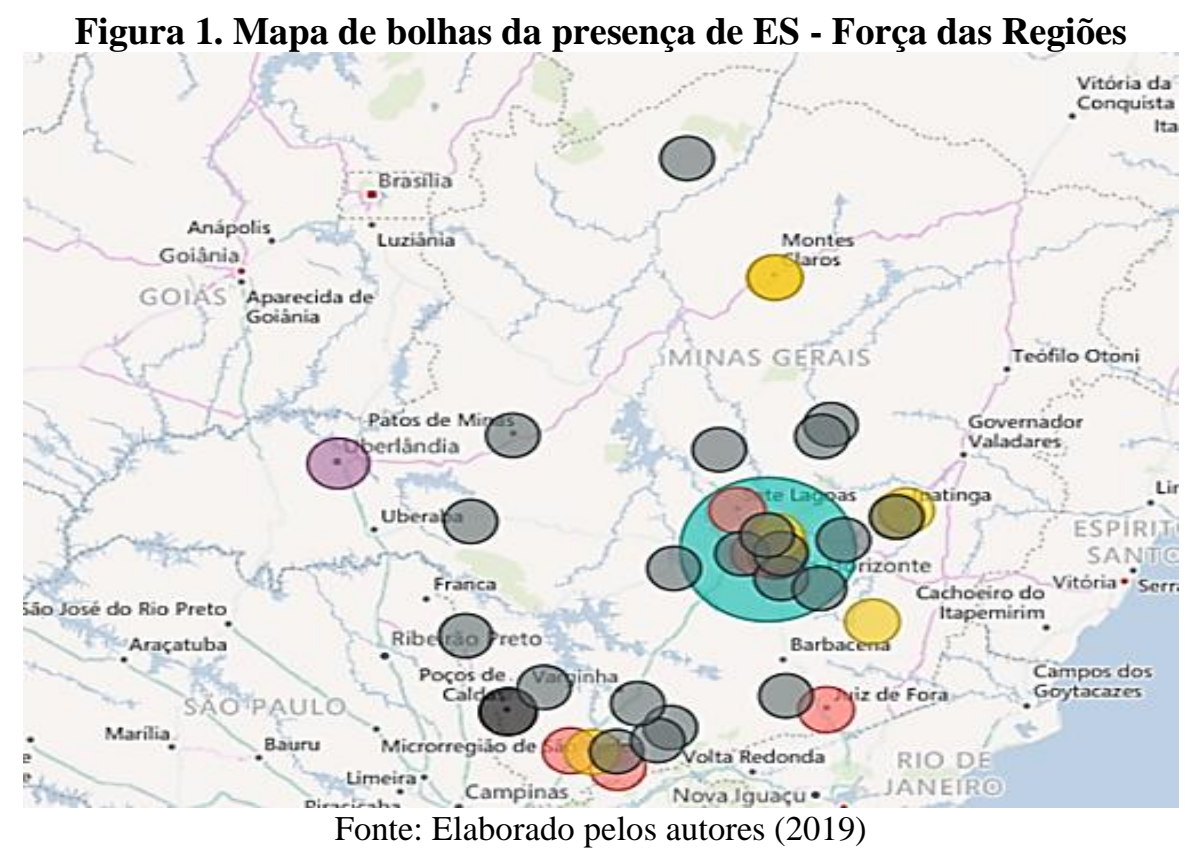

Por meio dessa observação, é possível afirmar que grande parte das ES identificadas se encontram, respectivamente, nas regiões Metropolitana, Sul e Sudoeste e Triângulo Mineiro e Alto Paranaíba. As representações apresentadas anteriormente servem de base para que a discussão seja desenvolvida levando em consideração os conglomerados formados por tais regiões do estado, sendo a partir desse viés que os próximos dados serão apresentados e discutidos.

\section{"Qual é o foco do impacto das empresas sociais em Minas Gerais?"}

Uma vez identificadas, foram realizadas as classificações de cada ES dentro de dez possíveis áreas de impacto - estabelecidas com base em classificações já utilizadas por duas organizações especializadas em negócios de impacto social: Pipe Social e Artemísia - sendo 
elas Cidadania, Cidades (Habitação e/ou Mobilidade), Ecologia/Agricultura, E-comerce, Educação, Finanças Sociais, Meio ambiente, Rede e/ou Incubadora/Aceleradora, Saúde e Tecnologia Verde. Contudo, é importante salientar que as iniciativas mapeadas e analisadas poderiam se fazer presentes em mais de uma classificação se suas atividades pudessem impactar em múltiplos campos.

Quando aprofundamos a análise e estabelecemos ligações entre as variáveis "Região" e "Área de impacto", abre-se o leque sobre as possíveis prioridades, demandas e incentivos que cada região de Minas Gerais poderia possuir, para que ES possam ser criadas, desenvolvidas e administradas. Através dos resultados obtidos na análise da dispersão geográfica realizada anteriormente, optou-se por abordar as aglomerações regionais mais pertinentes, sendo a Metropolitana, Sul e Sudoeste e Triângulo Mineiro e Alto Paranaíba. Enfatizando tais observações, apresenta-se a seguinte configuração das áreas de impacto por regiões mineiras:

\section{Gráfico 1. Atuação das ES mineiras por região}

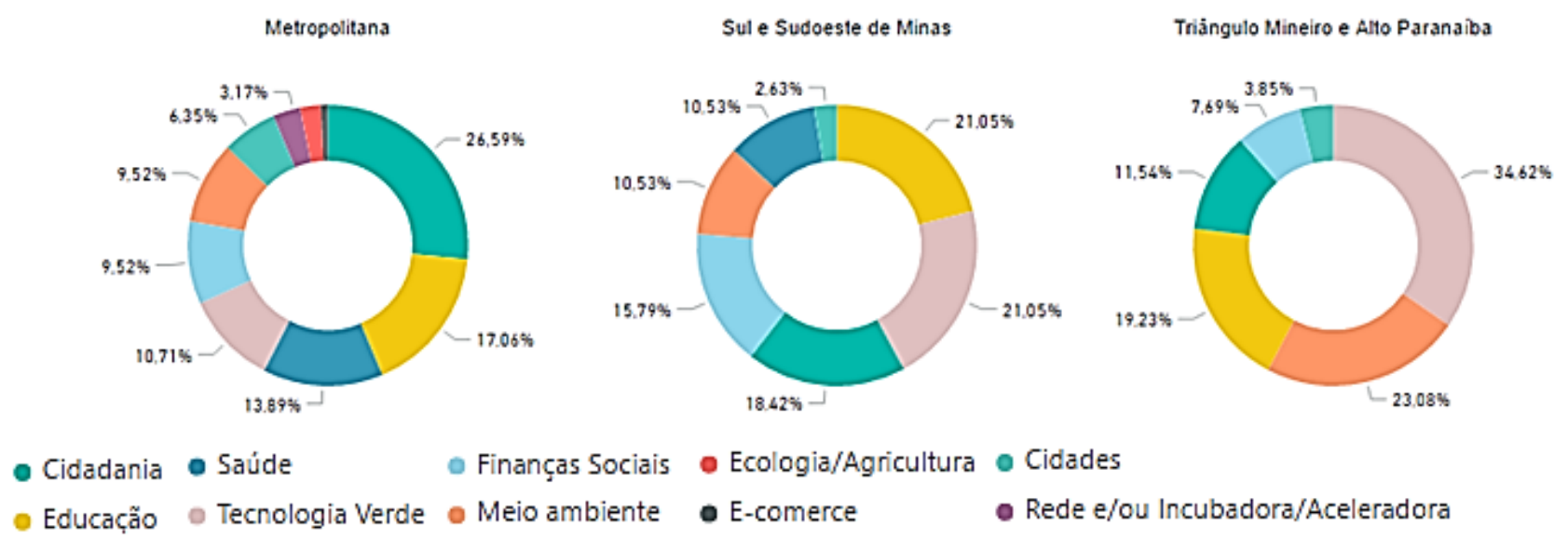

Fonte: Elaborado pelos autores (2019)

\section{Públicos impactados: "Para quem são as empresas sociais?"}

Ciente de sua localização e área de impacto, mostrou-se relevante identificar quais seriam os públicos, personagens e atores impactados com a forma na qual operam as ES mineiras identificadas. Para isso, foram levantadas 81 opções que, visando viabilidade à análise e apresentação dos dados, foram organizadas em 16 grupos, determinados de acordo com análises dos autores perante documentos, relatórios e artigos públicos cedidos pelas próprias ES em sites e mídias institucionais.

Obteve-se os seguintes grupos: Alunos, Profissionais e Instituições de ensino; Comunidade LGBTQ; Crianças e Adolescentes; Empresas sociais, Organizações da sociedade civil e relacionados; Empresas Tradicionais (referimos as "Empresas Tradicionais" como aquelas pertencentes ao segundo setor, tendo seu objetivo único a geração de receita e lucro para fins particulares); Família; Formação de empreendedores (sociais ou não); Idosos; Moradores de centros urbanos; Mulheres; Outros; Pessoas com problemas de saúde/necessidades especiais (menos idosos); Pessoas em vulnerabilidade social; População rural; Setor público e Sociedade em geral. 
Sardanha (2013), enfatiza que o impacto gerado por ES não se restringe ao consumidor final, chegando também às partes interessadas, como funcionários, governo, sociedade, comunidade, entre outras. Com base em tal argumento, as empresas foram classificadas em mais de um grupo, claro, se fosse necessário. Assim, uma empresa social poderia gerar impacto em mais de um público, dependendo do seu tipo de atividade. Com base em tais aspectos, obteve-se a seguinte distribuição percentual de acordo com as três principais regiões destacadas anteriormente - Metropolitana, Sul e Sudoeste e Triângulo Mineiro e Alto Paranaíba:

\section{Gráfico 2. Públicos impactados por regiões do estado}

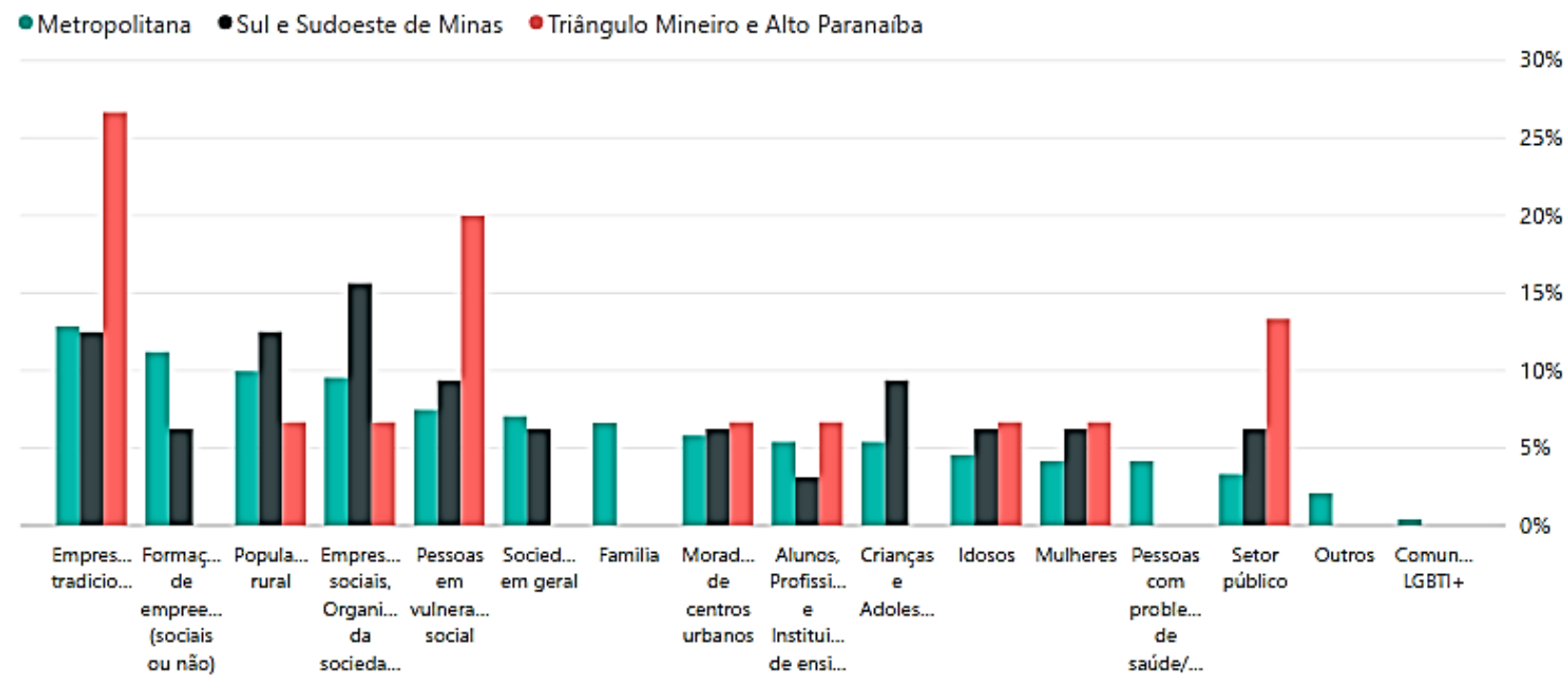

Fonte: Elaborado pelos autores (2019)

A configuração estabelecida acima possibilita a observação de frequente ocorrência de atividades voltadas às empresas tradicionais, sendo elas o principal público impactado pelas atividades das ES nas regiões Metropolitana e Triângulo Mineiro e a terceira mais impactada na região Sul e Sudoeste de Minas. Como a análise em questão é preliminar, não é possível identificar qual a natureza dessa relação apesar dessas iniciativas serem as detentoras de maior capital financeiro no sistema econômico em que estamos inseridos.

Focalizando a análise por região, nota-se que as ES localizadas no Triângulo Mineiro e Alto Paranaíba têm as empresas tradicionais como maior público impactado, seguido de pessoas em vulnerabilidade social e setor público. Tais públicos são tendências de atividades das ES no país, como demonstrado pelo senso do Pipe Social de 2019. Contudo, vale salientar que o setor público ainda é pouco explorado, mesmo tendo demonstrado se configurar como um parceiro potente para as iniciativas em questão. Não foram encontradas iniciativas que trabalhassem com a Formação de Empreendimentos (sociais ou não), Crianças e Adolescentes, Sociedade em geral - sendo atuações relevantes nas demais regiões analisadas Família, Pessoas com problemas de saúde/necessidades especiais (menos idosos) e Comunidade LGBTQ. Os campos de atuação predominantes são voltados para Tecnologias Verdes, Meio Ambiente e Educação. 
As iniciativas do Sul e Sudoeste de Minas atuam mais fortemente em ações voltadas à Empresas sociais, Organizações da sociedade civil e relacionados, além da População Rural e Empresas Tradicionais. Na pesquisa em questão, não foi encontrada atuação direcionada à Família, Pessoas com problemas de saúde/necessidades especiais (menos idosos) e Comunidade LGBTI+. O campo de atuação da região é focado em Tecnologia Verde, Educação e Cidadania.

Por fim, apresentando algumas diferenciações em relação ao interior, possivelmente em decorrência de suas especificidades enquanto capital e pólo industrial, por um lado, e pequenas cidades de produção agrícola, por outro, a região metropolitana concentra mais iniciativas focadas em Empresas Tradicionais, Formação de empreendedores sociais ou não e População rural. Contemplam todos os públicos alvo, tendo a Comunidade LGBTI+ e Setor Público como os menos frequentes. A atuação predominante refere-se a atividades envolvendo as áreas de Cidadania, Educação e Saúde.

\section{Negócios que impactam o social ou o social impactando os negócios?}

Santana (2015) destaca que o Brasil, devido a diferentes elementos presentes na história social, política, econômica e cultural do país, tem considerável potencial de desenvolver ES relevantes ou que, de fato, poderiam atender às demandas sociais, principalmente voltadas à desigualdade da social. E é nesse contexto nacional que Minas Gerais, conforme os resultados apurados, tem se demonstrado como um potencial ecossistema desses tipos de empreendimento.

De acordo com os resultados observados, pode-se observar que as regiões "Metropolitana", "Sul e Sudoeste de Minas" e "Triângulo Mineiro e Alto Paranaíba" são, nessa ordem, as regiões com maiores incidências de ES. Ao fazer relações com o PIB do estado, essas mesmas três regiões pontuam como as detentoras dos maiores valores encontrados em Minas Gerais. Essa constatação pode indicar a presença de maiores possibilidades de investimento e/ou apoio governamental voltadas para esse tipo de negócio.

Ainda sobre essas regiões, vale a pena destacar a influência cultural, política e social que a proximidade do estado de São Paulo poderia causar. São Paulo aparece hoje como a unidade federativa com maior concentração de ES e aceleradoras no Brasil, sendo uma das principais referências nacionais nesse campo (PIPE, 2017).

Corroborando ao que fora descrito acima, o relatório sobre as "Regiões de Influência das Cidades" publicados pelo Instituto Brasileiro de Geografia e Estatística (IBGE, 2007), destaca que as regiões presentes nas proximidades do estado de São Paulo, aquelas situadas em outros estados brasileiros, como parte do Triângulo Mineiro e do sul de Minas Gerais, estendendo-se a oeste pelos Estados de Mato Grosso e Mato Grosso do Sul, são marcadas por forte influência cultural, social, econômica e política paulista. Ademais, em São Paulo, cerca de $20 \%$ da população nacional estaria contida em sua região (IBGE, 2018), além de concentrar cerca de 33\% do Produto Interno Bruto, - PIB de 2016 - apresentando o maior percentual entre os estados brasileiros.

A alta concentração/primazia se reflete no PIB per capita, que é de $\mathrm{R} \$ 21,6$ mil para São Paulo, e R\$14,2 mil para os demais municípios do conjunto. De acordo com a mesma fonte, a rede formada por Belo Horizonte tem influência em cerca de 30,5\% da população do país que, contudo, não afetariam de maneira efetiva o Sul do seu próprio estado, além de 
compartilhar influência com a rede de São Paulo e Rio de Janeiro nas regiões do Triângulo Mineiro e da Zona da Mata, respectivamente. Tais pontos podem ser identificados no mapa de "região de influência" mineiro, apresentado abaixo:

Figura 2. Regiões de influência das cidades - Rede de Belo Horizonte

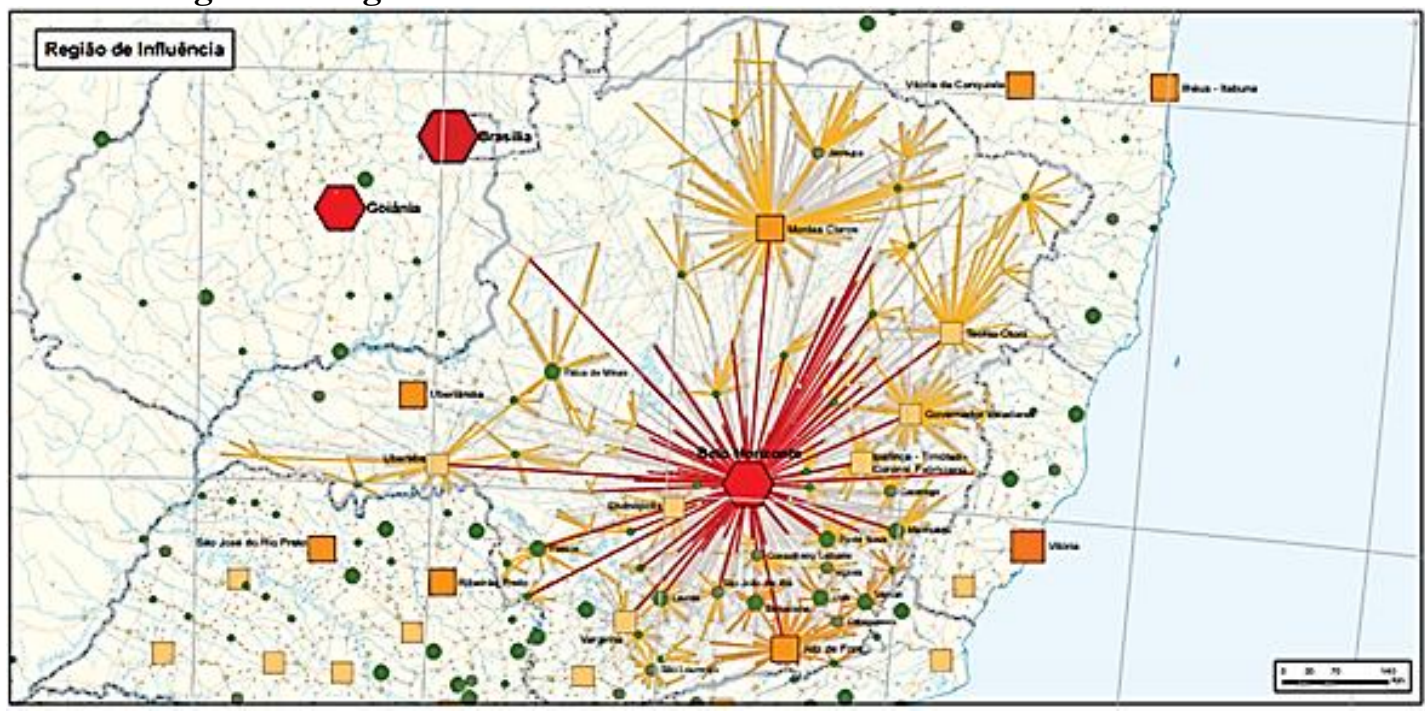

Fonte: IBGE (2007)

O mapa "região de influência" de São Paulo, produzido pelo IBGE, permite ilustrar os argumentos apresentados anteriormente e possibilitar a visualização do impacto da capital "São Paulo" em cidades situadas no próprio estado. Percebe-se também o avanço de fronteira e influência direta sobre o desenvolvimento de negócios em outros estados, como Minas Gerais, Paraná e Rio de Janeiro, reforçando a força influenciadora do estado de São Paulo.

Figura 3. Regiões de influência das cidades - Rede de São Paulo

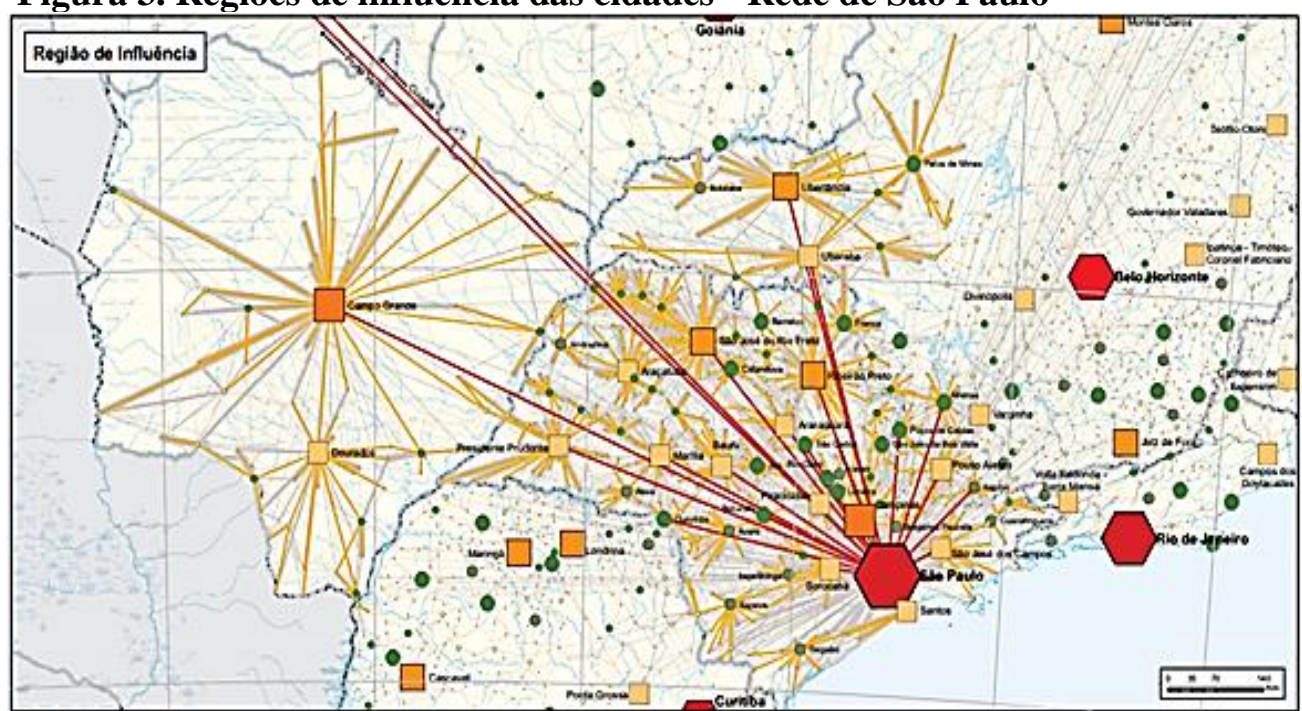

Fonte: IBGE (2007) 
Tais características citadas vão de encontro às constatações feitas pelo IBGE (2007), que afirma que a rede formada por São Paulo realiza intensas relações empresariais no próprio estado, na rede Rio de Janeiro, no sul de Minas Gerais, no norte do Paraná e em diversas regiões do país. Lobo e Matos (2011) e Azzoni (1986) afirmam que a região Metropolitana de São Paulo não deve ser referência para análise das alterações espaciais apenas no contexto do estado paulista, mas sim considerando um campo aglomerativo que inclui um conjunto maior, abrangendo várias cidades, num raio de aproximadamente $150 \mathrm{~km}$ da Região Metropolitana. Segundo o autor, esse campo exerce uma forte força de atração sobre os investimentos nessas cidades e, consequentemente, sobre a população. Os autores completam que a medida que aparecem novos avanços tecnológicos, esse campo aglomerativo amplia-se e reduz o próprio poder de atração do núcleo central.

Se por um lado o desenvolvimento da região metropolitana, Sul e Sudoeste de Minas, Triângulo Mineiro e Alto Paranaíba chamam atenção pela quantidade de negócios e influência de Belo Horizonte e São Paulo, o Norte de Minas, Vale do Mucuri e Vale do Jequitinhonha demonstram considerável carência de iniciativas empresariais. Esse dado nos remete aos estudos de Galvarro et al. (2009), que contextualizam Minas Gerais como um dos estados que mais apresentam disparidades regionais, visto que nele é possível encontrar regiões dinâmicas e modernas, contrastando com regiões atrasadas e estagnadas.

Minas Gerais é um estado de grandes contrastes socioeconômicos, que possui regiões dotadas de grande dinamismo econômico, como o Sul de Minas, o Triângulo e a Metropolitana de Belo Horizonte, que contrastam com áreas economicamente deprimidas, com infraestrutura deficiente e baixíssimos indicadores de qualidade de vida, como Norte de Minas, Jequitinhonha e Vale do Mucuri, regiões que, por características físicas e pela sua localização geográfica apresentam também baixa capacidade de arrecadação. (GALVARRO et al., 2009, p.37)

Costa et al. (2012) chamam atenção para o fato de que o desenvolvimento econômico e social não ocorre de maneira igual e simultânea em todos os locais. A isto podemos acrescentar que Minas Gerais apresenta o maior número de municípios do Brasil - são 863 no total. Viera et al. (2007) também corroboram estas diferenças no processo de desenvolvimento econômico e social, afirmando que não se configuram de maneira homogênea ao longo do estado de Minas Gerais. Nesse sentido, percebe-se que a proximidade com o estado de São Paulo ou com a capital Belo Horizonte poderia ajudar a promover o desenvolvimento de ES. No caso de regiões como o Norte de Minas e entorno, distantes de metrópoles, essa ausência de referências que possam impulsionar o desenvolvimento mostrase evidente nos resultados encontrados na pesquisa.

Oliveira (2008) corrobora essa hipótese ao afirmar que a eliminação de desigualdades regionais se torna possível, em conjunto com outros fatores, por meio do desenvolvimento de atividades interdependentes entre as regiões menos desenvolvidas e as desenvolvidas. Não obstante, o autor também chama atenção para a importância da atuação do Estado (Primeiro Setor) para intervir nas causas de deficiências de regiões subdesenvolvidas, destacando que são locais que demandam esforços que dependem de iniciativas consistentes e que vão muito além de iniciativas do mercado em si (Segundo Setor) e da sociedade civil (Terceiro Setor), isoladamente. 
Dessa forma, pelos dados iniciais coletados na pesquisa, percebe-se a diferença de desenvolvimento de ES no estado de Minas Gerais, apresentando visível polarização entre a região Norte com o Centro e Sul. Em seus estudos sobre disparidades inter- regionais, Costa et al. (2012) constatam exatamente que nas regiões do Triângulo Mineiro/Alto Paranaíba, Sul e região metropolitana de Belo Horizonte, localizam-se a maior parte dos municípios que possuem melhor estrutura socioeconômica. Já nas regiões localizadas ao norte do Estado, que incluem Vale do Mucuri e Vale do Jequitinhonha, se concentra o maior número de municípios com uma estrutura socioeconômica considerada pior que as demais.

Uma forma de observar essa disparidade geográfica no estado é por meio da leitura do Índice de Vulnerabilidade Social (IVS) realizado pelo Instituto de Pesquisa Econômica Aplicada (IPEA). A partir dos indicadores de Infraestrutura Urbana, Capital Humano e Renda e Trabalho é possível identificar dentro de cada município, estado ou país quais são os territórios com maior ou menor vulnerabilidade e suas particularidades. Os resultados demonstrados no mapa abaixo ajudam a ilustrar o contraste socioeconômico e geográfico presente em Minas Gerais. De fato, tais informações apontam as contradições das ES presentes no contexto mineiro, localizando-se em locais com alta concentração de renda e "muito baixa" vulnerabilidade social.

Figura 4. Índice de Vulnerabilidade Social por município em Minas Gerais

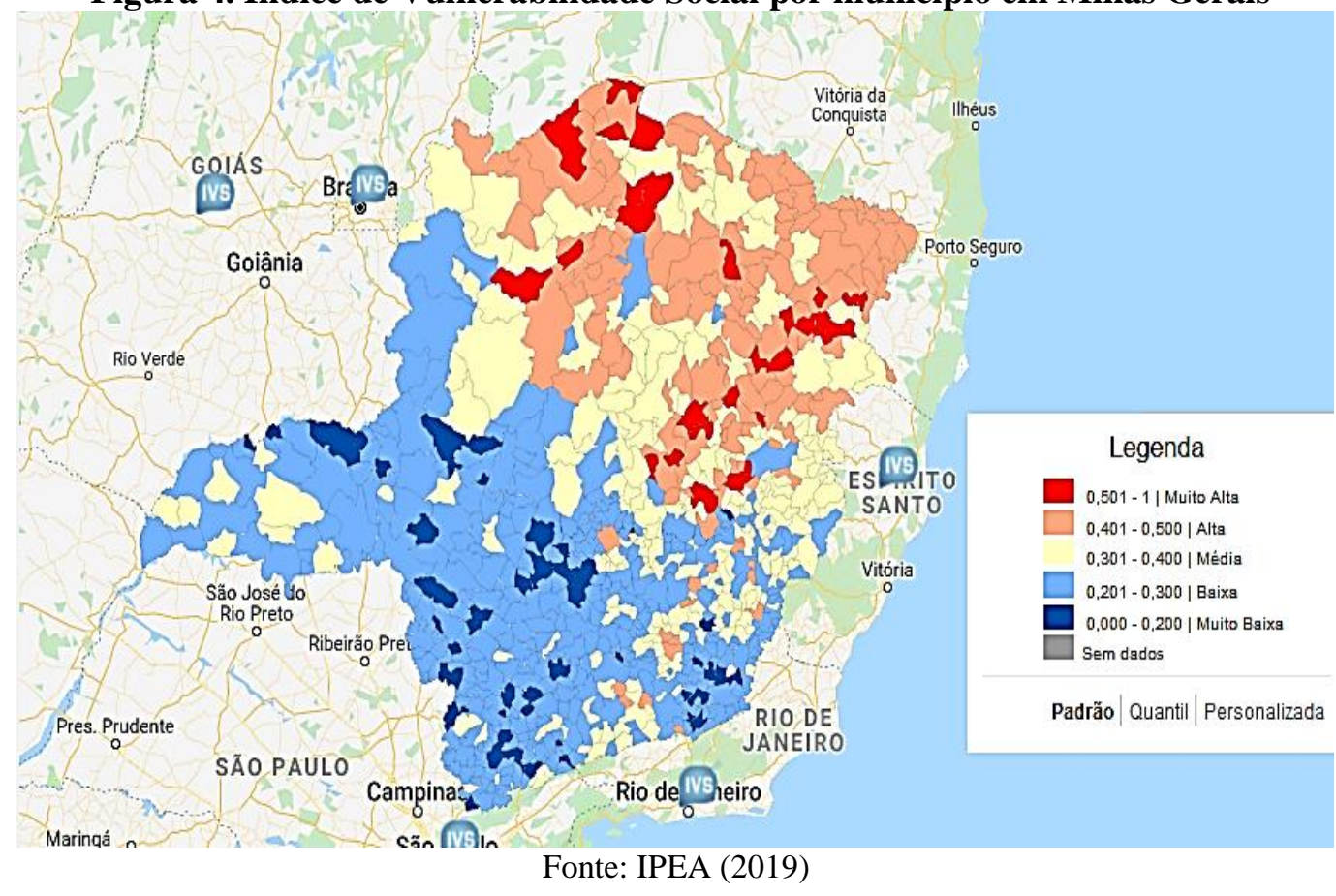

Se por um lado a proximidade com centros dinâmicos de geração de negócios, tradicionais ou não, como São Paulo e as regiões desenvolvidas de Minas Gerais, é compreensível pelo potencial de geração de ideias, relações e interações entre agentes de mercado e investidores e concentração de capital para investimento em ES; por outro lado, essa concentração denota também distanciamento justamente das regiões nas quais encontram-se os mais graves problemas sociais e ambientais do estado. Mesmo que ES 
criadas nos centros dinâmicos se voltem para a realidade das regiões menos favorecidas, deve-se considerar que o distanciamento geográfico espelha também distanciamento das iniciativas de ES e de seus idealizadores, impulsionadores e apoiadores com relação às populações e comunidades que residem em territórios marcados pela desigualdade social, a vulnerabilidade econômica e problemas ambientais. Esse distanciamento pode gerar graves problemas de compreensão da realidade social, levando os empreendimentos de ES a se constituírem a partir de diagnósticos parciais e precários sobre territórios e comunidades, desconsiderando saberes e conhecimentos locais, tácitos e socioambientais que são essenciais para o sucesso de ES e para a geração de inovações sociais efetivamente relevantes.

\section{Considerações Finais}

$\mathrm{O}$ artigo traçou um perfil inicial das ES em Minas Gerais, realizando o mapeamento daquelas que são atuantes no estado e identificando como estão distribuídas entre as regiões, destacando suas áreas de atuação e públicos impactados e, consequentemente, as possíveis variáveis que influenciam diretamente ou indiretamente na sua dispersão geográfica. Pode-se dizer que tal proposta se configurou como o primeiro passo de um conjunto de investigações que visam avançar na compreensão das ES na dinâmica do estado analisado. Guimarães et al. (2018) afirmam que Minas Gerais é um dos mais importante pólos inovadores não apenas do Brasil, mas também da América Latina, e possui grande potencial cultural, social e ambiental para desenvolver ES relevantes (SANTANA, 2015).

Uma importante contribuição do estudo foi o cruzamento de informações sobre as incidências de ES em diferentes regiões de Minas Gerais, suas atuações e públicos impactados, com fatores ambientais internos e externos ao estado, como redes de influências nacionais, a relação com o PIB e as disparidades socioeconômicas regionais mineiras. Esse percurso trouxe indagações sobre fatores que poderiam explicar como ocorre o surgimento e desenvolvimento de negócios do tipo. Esses fatores podem estar relacionados ao PIB da região, pela influência decorrente da proximidade de centros que são referências no desenvolvimento e apoio a negócios tradicionais e também de ES, como o estado São Paulo e a capital de Minas Gerais, Belo Horizonte.

Os estudos de disparidade inter-regionais e os dados encontrados no mapeamento de ES colocam uma questão crucial na discussão: essas iniciativas estão ocorrendo onde existem demandas sociais e ambientais para negócios deste tipo ou em regiões onde se encontra boa infraestrutura e investimentos? Considerando que as mesorregiões Norte de Minas, Jequitinhonha, Vale do Mucuri e Vale do Rio Doce, apresentam baixo desenvolvimento econômico e condições socioeconômicas precárias (GALVARRO et al., 2009), as ES, de acordo com sua essência, não deveriam ocorrer justamente nessas regiões?

Dessa forma, surgem novos questionamentos bastante incômodos para aqueles que advogam, às vezes de forma cega, a defesa intransigente das ES como alternativa de combate à pobreza, promoção da sustentabilidade e mitigação da desigualdade no país. São incômodas algumas dessas perguntas: Se as ES buscam através de atividades empresariais sanar problemas sociais, por qual motivo seria tão incipiente a participação efetiva em localidades como o Norte de Minas e entorno, que demandam tanto tais ações? Se a intenção é promover iniciativas que impactem a vida de pessoas socialmente vulneráveis, porque isso não ocorre nas regiões mais pobres? 
Além desses questionamentos, é importante aqui salientar que notou-se próxima relação entre as ES mineiras com as empresas tradicionais. Contudo, tal estudo não obteve informações pertinentes para explicação desse fenômeno. Devido a esse contexto, faz-se válido que em futuros estudos essa relação seja explorada com maior profundidade. Como se dá a relação entre as ES e as empresas tradicionais? Esse tipo de atuação transborda para outros públicos? Seriam a ES, de fato, um apêndice dessas empresas tradicionais? São essas algumas lacunas importantes à serem respondidas.

Ao mesmo tempo que a presente investigação trouxe elementos de discussão, o estudo aponta a necessidade de continuidade da pesquisa, apresentando outros fatores além dos já problematizados para se compreender em maior profundidade os impactos e implicações das ES no estado de Minas Gerais. Um dos elementos que não foi problematizado na pesquisa atual e que nos parece central em investigações futuras diz respeito às relações entre atores do estado, do mercado e da sociedade civil nos territórios ou regiões marcados por elevado PIB e IDH e naqueles marcados por graves desigualdades de PIB e IDH entre suas populações e comunidades.

Encerramos este artigo reafirmando a necessidade e importância de continuidade nas investigações, uma vez que se trata de um assunto que vem ganhando destaque em pesquisas acadêmicas no Brasil e no mundo e chamando a atenção por sua proposta diferenciada de geração de impacto social. Todavia, se a proposta é de fato gerar impacto em regiões e pessoas em situação de vulnerabilidade, é preciso saber se isso vem ocorrendo em contextos, territórios e grupos que não se constituem naqueles mais afetados pelos problemas socioambientais ou se, talvez, ainda não existam estratégias para atuação em localidades realmente pobres. É preciso saber se as Empresas Sociais vêm processando seu organizing, incluindo-se aí sua localização territorial, de forma tradicional, reproduzindo o "business as usual" ou se realmente contém a potência transformadora, inovadora e disruptiva que tanto afirmam ter os diferentes atores do ecossistema de ES que estão comprometidos com a sua expansão em Minas Gerais e no Brasil.

\section{Referências}

ABRAMOVAY, R. (2012). Muito além da economia verde. Editora Abril.

AMBROSE-OJI, B., LAWRENCE, A., \& STEWART, A. (2015). Community based forest enterprises in Britain: Two organising typologies. Forest Policy and Economics, 58, 65-74.

BARKI, E. (2015) Negócios de Impacto: tendência ou modismo? GVexecutivo, v. 14, n. 1, p. 14-17.

BESLEY, T., \& GHATAK, M. (2017). Profit with purpose? A theory of social enterprise. American Economic Journal: Economic Policy, 9(3), 19-58.

BRANDÃO, D.; CRUZ, C.; ARIDA, A. L. (2013) Métricas em negócios de impacto social: fundamentos. São Paulo: MOVE, Instituto de Cidadania Empresarial.

COMINI, G. M. (2016) Negócios sociais e inovação social: um retrato de experiências brasileiras. São Paulo, 166 p. Tese (Livre-Docência) - Universidade de São Paulo, 2016. Disponível em http://www.teses.usp.br/teses/disponiveis/livredocencia/12/tde-15122016143942/pt-br.php. Acesso em 10 de fev. de 2019.

COMINI, G. M., BARKI, E., \& AGUIAR, L. (2013) O novo campo dos negócios com impacto social. In Negócios com impacto social no Brasil. São Paulo: Petrópolis. 
COMINI, G.; BARKI, E.; AGUIAR, L. (2012) A three-pronged approach to social business: a Brazilian multi-case analysis. Revista de Administração, v.47, n.3, p.385-397, 2012.

COSTA M.; FERREIRA M.; BRAGA J.; ABRANTES A. (2012) Disparidades interregionais e características dos municípios do estado de Minas Gerais. Desenv Questão. maioago;10(20):52-88.

DEFOURNY, J., \& NYSSENS, M. (2017). Fundamentals for an international typology of social enterprise models. VOLUNTAS: International Journal of Voluntary and Nonprofit Organizations, 28(6), 2469-2497.

DEFOURNY, J.; NYSSENS, M. (2012) "El enfoque EMES de empresa social desde una perspectiva comparada", CIRIEC-España, Revista de Economía Pública, Social y Cooperativa, 75, 7-34.

FERREIRA et al. (2014) Negócio social, Empreendedorismo social e Empresa social: Termos distintos, mesmo objetivo. VIII Encontro de Estudos em Empreendedorismo e Gestão de pequenas Empresas. Goiânia.

FRIEDMAN, M. (1970) The social responsibility of business is to increase its profits. New York Times Magazine, September 13: 32-33, 122-124.

GALVARRO, M. D. P. S. Q. S.; BRAGA, M. J.; FERREIRA, M. A. M.; OLIVEIRA, S. (2009) Disparidades regionais na capacidade de arrecadação dos municípios do estado de Minas Gerais. Revista de Economia e Administração, v. 8, n. 1, p. 17-48.

HART. S. (2005) Capitalismo na encruzilhada. Porto Alegre, Bookman.

INSTITUTO BRASILEIRO DE GEOGRAFIA E ESTATÍSTICA - IBGE. Disponível em:

<http://www.ibge.gov.br>. Acesso em: 14 mai. 2019.

INSTITUTO DE PESQUISA ECONÔMICA APLICADA (IPEA). Disponível em:

<http://www.ipea.gov.br/portal/>. Acesso em: 04 jun. 2019.

Região de influência das cidades 2007. Rio de Janeiro: IBGE. 2008. Disponível em: <http://www.ibge.gov.br/home/geociencias/geografia/regic.shtm?c=6/>.Acesso em: 14 mai. 2019

JOÃO, I. S. (2012) Empresa Social: Um conceito pendente de consenso. Centro de Investigación en Economía y Sociedad (CIES), Barcelona, ES, n. 97, Agosto.

LOBO, C.; MATOS, R. (2011) Migrações e a dispersão espacial da população nas regiões de Influência das principais metrópoles Brasileiras. Rev. bras. estud. popul., São Paulo, v. 28, n. 1, p. 81-101, June.

MAIR, J.; MARTÍ, I. (2006) Social entrepreneurship research: A source of explanation, prediction, and delight. Journal of World Business, 41(1), 36-44.

MAIR, J; ROBINSON, J., HOCKERTS, K. (2006) Social Entrepreneurship. New York: Palgrave MacMillan.

MIRON JAPPE, M. L. (2013) Fatores contributivos e fatores limitadores para negócios sociais no Brasil: Um estudo exploratório nas regiões sul e sudeste. 2013. 96 f. Dissertação (Mestrado em Administração) - Escola de Administração, Universidade Federal do Rio Grande do Sul, Porto Alegre.

MSWAKA, W., \& Aluko, O. (2015). Corporate governance practices and outcomes in social enterprises in the UK: A case study of South Yorkshire. International journal of public sector management, 28(1), 57-71. 
MUNOZ, S. A., Farmer, J., Winterton, R., \& Barraket, J. (2015). The social enterprise as a space of well-being: an exploratory case study. Social Enterprise Journal, 11(3), 281-302.

OLIVEIRA, J. C. (2008) Análise do crescimento econômico e das desigualdades regionais no Brasil. Estudos do Cepe, Santa Cruz do Sul, n. 28, p. 5-28, jul./dez.

PETRINI, M.; SCHERER, P.; BACK, L. (2016) Modelo de negócios com impacto social. Revista de Administração de Empresas, v. 56, n. 2, p. 209-225.

PRAHALAD, C. K. (2010) A riqueza na base da pirâmide: como erradicar a pobreza com o lucro. 2 ed. Porto Alegre: Bookman.

PRAHALAD, C. K. (2005) Servindo aos pobres do mundo, com lucro. In: Ética e Responsabilidade Social nas empresas. Harvard Business Review, Rio de Janeiro: Editora Campus.

PRAHALAD, C. K.; HART, S. L. (2002) The fortune at the Bottom of the Pyramid. Strategy and Business, v.26.

ROMANI-DIAS, M.; IISUKA, E. S. (2016) NEGÓCIOS SOCIAIS: Estudo Bibliométrico e Análise Sistemática da Literatura Nacional e Internacional. São Paulo.

ROSOLEN, T. TISCOSKI, G. P; COMINI, G. M. (2014) Empreendedorismo Social e Negócios Sociais: um estudo bibliométrico da publicação nacional e internacional. Revista Interdisciplinar de Gestão Social, Salvador, v. 3, n. 1, p. 85-105.

SANTANA, A. L. J. M. (2015) Empreendedorismo com foco em negócios sociais. Curitiba: NITS UFPR.

SARDANHA, G. (2013) Social business and Grameen Danone foods limited. Society and Business Review, Bingley, 8(2), 119-133.

TEODÓSIO, A. D. S. S.; COMINI, G. (2012) Inclusive business and poverty: prospects in the Brazilian context. Revista de Administração, v. 47, n. 3, p. 410-421.

VIEIRA, M. A.; ABRANTES, L. A.; FERREIRA, M. A. M.; LOPES, J. V. S. (2017)

Implicações do Esforço de Arrecadação no Desempenho Socioeconômico dos Municípios de Minas Gerais. Gestão \& Regionalidade, v. 33, n. 99, p. 21-38.

YUNUS, M. Discurso na cerimônia de entrega do Prêmio Nobel. 2006. Disponível: http://www.permear.org.br/pastas/documentos/permacultor4/Banco-Grameen.pdf. Acesso em 28 de Jan de 2019.

YUNUS, M. (2017) A World of Three Zeros. The New Economics of Zero Poverty, Zero Unemployment, and Zero Net Carbon Emission. New York: Public Affairs.

YUNUS, M.; MOINGEON, B.; LEHMANN-ORTEGA, L. (2009) Building social business models: lessons from the Grameen experience. Paris: HEC. (Working Paper, 913) 